OPEN ACCESS

Edited by:

Guochang $\mathrm{Hu}$,

University of Illinois at Chicago,

United States

Reviewed by:

Monowar Aziz,

Feinstein Institute for Medical

Research, United States

Samithamby Jey Jeyaseelan,

Louisiana State University,

United States

Lin Zou,

University of Maryland, Baltimore,

United States

*Correspondence:

Guo-Chang Fan

fangg@ucmail.uc.edu

Specialty section:

This article was submitted to

Inflammation,

a section of the journal

Frontiers in Immunology

Received: 29 December 2020

Accepted: 26 January 2021

Published: 17 February 2021

Citation:

Wang P, Mu X, Zhao H, Li Y, Wang L, Wolfe $V$, Cui S-N, Wang $X$, Peng $T$, Zingarelli $B$, Wang $C$ and Fan $G-C$ (2021) Administration of GDF3 Into Septic Mice Improves Survival via

Enhancing LXR $\alpha$-Mediated

Macrophage Phagocytosis.

Front. Immunol. 12:647070.

doi: 10.3389/fimmu.2021.647070

\section{Administration of GDF3 Into Septic Mice Improves Survival via Enhancing LXR $\alpha$-Mediated Macrophage Phagocytosis}

\author{
Peng Wang ${ }^{1,2}$, Xingjiang $\mathrm{Mu}^{2}$, Hongyan Zhao ${ }^{2,3}$, Yutian $\mathrm{Li}^{2}$, Lu Wang ${ }^{2,4}$, Vivian Wolfe ${ }^{5,6}$, \\ Shu-Nan Cui ${ }^{2,7}$, Xiaohong Wang ${ }^{2}$, Tianqing Peng ${ }^{8}$, Basilia Zingarelli ${ }^{5,6}$, Chunting Wang ${ }^{1}$ \\ and Guo-Chang Fan ${ }^{2 *}$ \\ ${ }^{1}$ Department of Critical Care Medicine, Shandong Provincial Hospital Affiliated to Shandong First Medical University, Jinan, \\ China, ${ }^{2}$ Department of Pharmacology and Systems Physiology, University of Cincinnati College of Medicine, Cincinnati, OH, \\ United States, ${ }^{3}$ Department of Critical Care Medicine, The Second Hospital, Cheeloo College of Medicine, Shandong \\ University, Jinan, China, ${ }^{4}$ Department of Critical Care Medicine, Renmin Hospital of Wuhan University, Wuhan, China, \\ ${ }^{5}$ Division of Critical Care Medicine, Cincinnati Children's Hospital Medical Center, Cincinnati, OH, United States, \\ ${ }^{6}$ Department of Pediatrics, University of Cincinnati College of Medicine, Cincinnati, OH, United States, ${ }^{7}$ Department of \\ Anesthesiology, Beijing Cancer Hospital, Peking University School of Oncology, Beijing, China, ${ }^{8}$ The Centre for Critical Illness \\ Research, Lawson Health Research Institute, London, ON, Canada
}

The defective eradication of invading pathogens is a major cause of death in sepsis. As professional phagocytic cells, macrophages actively engulf/kill microorganisms and play essential roles in innate immune response against pathogens. Growth differentiation factor 3 (GDF3) was previously implicated as an important modulator of inflammatory response upon acute sterile injury. In this study, administration of recombinant GDF3 protein (rGDF3) either before or after CLP surgery remarkably improved mouse survival, along with significant reductions in bacterial load, plasma pro-inflammatory cytokine levels, and organ damage. Notably, our in vitro experiments revealed that rGDF3 treatment substantially promoted macrophage phagocytosis and intracellular killing of bacteria in a dose-dependent manner. Mechanistically, RNA-seq analysis results showed that CD5L, known to be regulated by liver $X$ receptor $\alpha(L X R \alpha)$, was the most significantly upregulated gene in rGDF3-treated macrophages. Furthermore, we observed that rGDF3 could promote $\mathrm{LXR} \alpha$ nuclear translocation and thereby, augmented phagocytosis activity in macrophages, which was similar as LXR $\alpha$ agonist GW3965 did. By contrast, pre-treating macrophages with $L X R \alpha$ antagonist GSK2033 abolished beneficial effects of rGDF3 in macrophages. In addition, rGDF3 treatment failed to enhance bacteria uptake and killing in LXR $\alpha$-knockout $(\mathrm{KO})$ macrophages. Taken together, these results uncover that GDF3 may represent a novel mediator for controlling bacterial infection.

Keywords: growth differentiation factor 3, macrophage, phagocytosis, sepsis, LXR $\alpha$, CD5L 


\section{INTRODUCTION}

Sepsis is characterized as life-threatening multi-organ dysfunction caused by a dysregulated host response to infection $(1,2)$. Although aggressive antibiotic treatments are applied to control bacterial infection at the early stage, sepsis remains a leading cause of death in intensive care units $(3,4)$. Recently, in a post-mortem study of 235 sepsis patients, about $80 \%$ of patients had unresolved septic foci at death (5), indicating that sepsis-induced death is closely associated with the failure of the host's immunity to eradicate invading pathogens $(6,7)$. Hence, it is becoming clear that sepsis is not only the result of excessive inflammation but also is coupled with defective immune system with impaired pathogen clearance function (1). However, there is currently lack of specific pharmacologic therapy that can target the host immune response to eradicate invading pathogens $(8,9)$, and drug-resistance bacteria are also emerging (10). Thus, it is urgently needed to develop alternative treatment strategies to enhance host defenses for timely clearance of bacteria (11).

Macrophages are the key components of the immune system, forming a bridge between innate and adaptive immunity by producing a myriad of cytokines, phagocytosing invading pathogens, and presenting antigens to other immune cells (12). As professional phagocytic cells, macrophages are vital to the resolution of inflammation through high endocytic clearance capacities and trophic factor synthesis, accompanied by reduced pro-inflammatory cytokine secretion (13). Patients with defects in the phagocytic function of macrophages are predisposed to intracellular microorganisms and typically manifest early dissemination of infection $(14,15)$. Therefore, to provide more efficacious therapies for sepsis, it would be very significant to better understand macrophage function and the underlying mechanisms that govern phagocytosis.

As a member of TGF- $\beta$ superfamily, GDF3 was initially identified in stem cells during early embryonic development (1618). Later work defined it as an adipogenic cytokine regulating adipose tissue homeostasis and energy balance (19-21), and a marker of stem cells $(22,23)$. Recently, several studies suggest that GDF3 might play a vital role in modulating inflammatory response upon acute sterile injury $(24,25)$. For example, Varga et al. reported that GDF3 could serve as a macrophage-derived factor in tissue repair during skeletal muscle regeneration (24). Patsalos et al. further demonstrated that in vivo administration of GDF3 could compensate for the age-related loss of reparative macrophages, which improved the kinetics of muscle repair following acute sterile injury (25). Furthermore, our recent studies revealed that serum GDF3 levels in septic patients are elevated and strongly correlate with severity of sepsis and 28-day mortality (26). However, macrophages treated with recombinant GDF3 protein (rGDF3) exhibit reduced production of proinflammatory cytokines, compared to controls upon endotoxin challenge (26). Therefore, these prior findings promoted us to clarify whether GDF3 could regulate macrophage phagocytic function in a clinically relevant sepsis model.

In this study, we observed that the administration of rGDF3 either before or after cecal ligation and puncture (CLP) surgery significantly decreased bacterial burden and systemic/local inflammation, alleviated multiple organ injury and animal mortality, compared to control mice. Mechanistically, we identified that rGDF3 treatment promoted phagocytosis and bacteria killing activity of macrophages through activation of LXR $\alpha$ pathway. Accordingly, rGDF3-mediated phagocytosis and bacterial killing were abolished in LXR $\alpha$-deficient macrophages or by pharmacological inhibition of the LXR $\alpha$ pathway using GSK2033 in macrophages. Therefore, our study indicates that GDF3 may play a previously unrecognized role in controlling bacterial dissemination during sepsis.

\section{MATERIALS AND METHODS}

\section{Mice}

C57BL/6J mice were purchased from Jackson Laboratories (Bar Harbor, ME, USA). The global LXR $\alpha$-KO mice were a gift from Dr. Basilia Zingarelli (Cincinnati Children's Hospital Medical Center, Cincinnati, OH). All mice were maintained and bred under specific pathogen-free conditions in the Division of Laboratory Animal Resources at the University of Cincinnati Medical Center. All animal experiments conformed to the Guidelines for the Care and Use of Laboratory Animals prepared by the National Academy of Sciences, published by the National Institutes of Health, and approved by the University of Cincinnati Animal Care and Use Committee.

\section{Polymicrobial Sepsis Model, Survival, and Bacterial Burden Assay}

Mouse polymicrobial sepsis was surgically induced by CLP as described previously (27). In brief, to determine whether rGDF3 had any preventive effects in vivo against polymicrobial sepsis, recombinant mouse GDF3 Protein $(20 \mu \mathrm{g} / \mathrm{kg}$ body weight) (R\&D Systems, Cat. \# 9009-GD-010) or BSA vesicle was injected into the tail vein of wild-type (WT) mice (8-week old, male) $3 \mathrm{~h}$ before CLP. Considering the cyclic hormonal changes during the ovulatory cycle in female mice might cause excess variability, male WT mice were used in the CLP model. Then, mice were anesthetized by intraperitoneal injection of a mixture of ketamine $(100 \mathrm{mg} / \mathrm{kg})$ and xylazine $(5 \mathrm{mg} / \mathrm{kg})$. A midline laparotomy was then performed. The cecum was exposed and ligated at $1.5 \mathrm{~cm}$ from the distal end with a 5-0 sterile silk suture. A single through and through puncture was made at the middle between the ligation and distal end of the cecum with a 21-gauge needle. After puncturing, the cecum was gently compressed to extrude a small amount of cecal content and returned to the abdominal cavity. The abdominal wall incision was closed in layers. After surgery, pre-warmed phosphate buffered saline $(0.05 \mathrm{~mL} / \mathrm{g}$ body weight $)$ was administered subcutaneously. Postoperative pain control was managed with $0.05 \mathrm{mg} / \mathrm{kg}$ buprenorphine every $12 \mathrm{~h}$. While, to examine the therapeutic effects of rGDF3 in WT mice upon CLP surgery, rGDF3 (100 $\mu \mathrm{g} / \mathrm{kg}$ body weight), or BSA vesicle was injected into the tail vein $1 \mathrm{~h}$ after CLP. In order to assess the actual effect of rGDF3 on the survival of septic mice, antibiotics was not used in the CLP model. The animal survival rate was monitored every $6 \mathrm{~h}$ for 7 days after CLP operation. Whole blood and peritoneal lavage fluid (PLF) were harvested from these mice to measure bacterial burden, cytokines, and markers of organ 
injury at 20-24 h post-CLP surgery. Bacterial burden assay was performed as described previously (28).

\section{Lung Histology and Lung Injury Score}

Lung tissues were collected from mice at $24 \mathrm{~h}$ post-CLP. All lungs were perfused via the heart, inflated and fixed with $10 \%$ buffered formalin for more than 2 days, then embedded in paraffin, and cut into $5-\mu \mathrm{m}$ sections. Tissue sections were stained with hematoxylin and eosin (H\&E). To evaluate the lung injury, 6-8 independent random lung fields were evaluated per mouse for neutrophils in alveolar spaces, neutrophils in the interstitial spaces, hyaline membranes, proteinaceous debris filling the airspaces, and alveolar septal thickening and weighted according to the relevance ascribed by the official American Thoracic Society workshop report on features and measurements of experimental acute lung injury in animals (29).

\section{Tissue Wet-to-Dry Weight Ratio}

To quantify the spleen and lung edema, whole spleen and lung tissues were collected at $24 \mathrm{~h}$ post-CLP, rinsed to remove surface blood and patted dry, and the immediate weights of the samples were recorded as the wet weight. The tissues were air dried for $48 \mathrm{~h}$ at $60^{\circ} \mathrm{C}$, and the weights were recorded as the dry weight. A wet/dry weight ratio for each individual mouse was calculated.

\section{Assessment of Liver and Kidney Injury}

Serum levels of alanine aminotransferase (ALT), a biochemical marker of liver injury, were measured using an ALT assay kit (MyBioSource, Cat. \# MBS264717). Serum levels of creatinine (Cr), a biochemical marker of kidney injury, were determined using a creatinine assay kit (MyBioSource, Cat. \# MBS2504918), according to manufacturers' protocols.

\section{Measurement of Cytokines}

Blood and PLF were collected at $20 \mathrm{~h}$ after CLP surgery and serum samples were prepared by centrifuged at 3,000 $\mathrm{g}$ for $15 \mathrm{~min}$ at $4^{\circ} \mathrm{C}$. All serum was stored in $-80^{\circ} \mathrm{C}$ until use. ELISAs were performed to measure the levels of TNF- $\alpha$ and IL- 6 in sera and PLF using commercially available kits [Peprotech, Cat. \# 900-K54 (TNF- $\alpha$ ), Cat. \# 900-K50 (IL-6)], according to the manufacturer's protocols.

\section{Cell Preparation}

For the isolation of peritoneal macrophages (PMs), $5 \mathrm{~mL}$ PBS was used to lavage the abdominal cavity of euthanized mice for three times. The PLF was collected and centrifuged (2,000 rpm, $5 \mathrm{~min}$ ). The cell pellet was then resuspended in $10 \mathrm{~mL}$ fresh prepared Dulbecco's modified Eagle medium (DMEM) media with 10\% fetal bovine serum (FBS) and 1\% penicillin/streptomycin. The cells were allowed to adhere to the substrate by culturing them for $4 \mathrm{~h}$ at $37^{\circ} \mathrm{C}$. Non-adherent cells were removed by gently washing three times with warm PBS. Adherent cells were cultured for $18 \mathrm{~h}$, and then used for experiments.

Bone marrow-derived macrophages (BMDMs) were isolated cultured/differentiated into macrophages as described previously (30). In brief, mice were terminally anesthetized, bone marrow from the tibias and femurs of mice was flushed out using cold sterile wash medium (DMEM), and filtered through $70 \mu \mathrm{m}$
Nylon cell strainer. Subsequently, these mononuclear cells were centrifuged at $500 \mathrm{~g}$ for $5 \mathrm{~min}$ at room temperature (RT). The resulting cell pellet was re-suspended in complete culture medium (DMEM supplemented with $10 \%$ of L929 cell culture supernatant, $10 \%$ FBS, $1 \%$ penicillin/streptomycin solution, and $1 \%$ HEPES), and cultured in a humidified atmosphere of $5 \%$ $\mathrm{CO}_{2}$ at $37^{\circ} \mathrm{C}$ for 7 days, culture medium was changed on Day 4 of culture.

RAW264.7 macrophages (mouse macrophage cell line) were cultured in incubator at $37^{\circ} \mathrm{C}$ with $5 \% \mathrm{CO}_{2}$. The cells grew in DMEM, containing 10\% FBS and 1\% penicillin/streptomycin.

\section{MTS Cell Proliferation Assay}

BMDMs and RAW264.7 macrophages seeded into 96-well plates were treated with different rGDF3 doses for $18 \mathrm{~h}$. Cell viability was measured by addition of 3-(4,5-dimethylthiazol-2-yl)-5(3-carboxymethoxyphenol)-2-(4-sulfophenyl)-2H-tetrazolium (MTS, Promega, USA) for $1.5 \mathrm{~h}$ at $37^{\circ} \mathrm{C}$. The absorbance was measured spectrophotometrically at $490 \mathrm{~nm}$ with a microplate reader (ELx800, Bio-Tek, USA) according to the manufacturer's protocols.

\section{Phagocytosis Assay With Escherichia coli BioParticles}

To analyze the phagocytic capacity of RAW264.7 macrophages and BMDMs isolated from WT mice, cells were seeded into 96-well plates $\left(4 \times 10^{4}\right.$ cells/well; or $1 \times 10^{5}$ cells/well $)$ or on coverslips in 24 -well plates $\left(5 \times 10^{4}\right.$ cells/well; or 2 $\times 10^{5}$ cells/well) in DMEM medium and allowed to adhere for $24 \mathrm{~h}$. Cells were treated with BSA, rGDF3 $(20 \mathrm{ng} / \mathrm{mL})$, GW3965 (1 $\mu \mathrm{mol} / \mathrm{L})$ or GSK2033 (2 $\mu \mathrm{mol} / \mathrm{L})+$ rGDF3 $(20 \mathrm{ng} / \mathrm{mL})$ for $18 \mathrm{~h}$, followed by the addition of pHrodo red E. coli BioParticles (Thermal Fisher Scientific, Cat. \# P35361) diluted in medium according to the manual. Subsequently, cells were incubated with BioParticles for $1.5 \mathrm{~h}$ at $37^{\circ} \mathrm{C}$. The fluorescence intensity was measured using a GloMax ${ }^{\circledR}$-Multi Detection System (Promega). While cells cultured on coverslips were stained with CellMask ${ }^{\mathrm{TM}}$ Green Plasma Membrane Stain (Invitrogen, Cat. \# C37608) as described in the manual. Then, cells were fixed with $4 \%$ paraformaldehyde (15 min RT). After washing three times with PBS, coverslips were mounted onto slides using a ProLong ${ }^{\mathrm{TM}}$ diamond antifade mountant reagent with DAPI (Invitrogen, Cat. \# P36962). Subsequently, slides were imaged with a confocal LSM 710 (Carl Zeiss Microimaging, Jena, Germany). Images were recorded with ZEN (Black) and analyzed with ImageJ software (Wayne Rasband, National Institutes of Health, Bethesda, MD).

\section{Flow Cytometry}

PMs isolated from WT mice were seeded into 6-well plates (8 $\times 10^{5}$ cells/well) in DMEM medium and allowed to adhere for $18 \mathrm{~h}$. Cells were treated with BSA or rGDF3 $(20 \mathrm{ng} / \mathrm{mL})$ for $18 \mathrm{~h}$, followed by the pHrodo red E. coli BioParticles according to the manual. Subsequently, cells were incubated with BioParticles for $1.5 \mathrm{~h}$ at $37^{\circ} \mathrm{C}$. Then, cells were collected and fixed with $2 \%$ paraformaldehyde (15 min on ice). After washing with FACS buffer, Flow cytometry analysis was performed. 


\section{Bacterial Phagocytosis and Killing Assay}

To determine bactericidal activity, a classical CFU assay was conducted with minor modifications as described previously (31). Briefly, E. coli DH5 alpha were grown overnight in LB at $37^{\circ} \mathrm{C}$. After that, bacteria were quantified, pelleted, and washed with PBS. BMDMs or RAW264.7 macrophages were placed in 12-well-culture plates and pre-incubated for $6 \mathrm{~h}$ to allow to adhere. Subsequently, cells were treated with BSA or rGDF3 $(20 \mathrm{ng} / \mathrm{mL})$ in antibiotic-free fresh medium for $18 \mathrm{~h}$. Cells were infected with live $E$. coli at a multiplicity of infection (MOI) of 20 bacteria/cell ratio for $1 \mathrm{~h}$ at $37^{\circ} \mathrm{C}$ with $5 \% \mathrm{CO}_{2}$. Fresh DMEM containing $100 \mu \mathrm{g} / \mathrm{mL}$ gentamicin was added and incubated for $30 \mathrm{~min}$ to kill extracellular bacteria. To determine internal bacteria, macrophages were washed two times with cold PBS and lysed. The cell lysate was diluted serially and plated on the LB plate to determine the colony-forming unit (CFU) count. To assess the bactericidal activity, cells were incubated for another $6 \mathrm{~h}$. The number of bacteria remained after intracellular killing was determined by lysing cells and plating the cell lysate as described in above. The killing percentage was calculated by using the formula $[(\mathrm{CFU}$ count at $1 \mathrm{~h})-(\mathrm{CFU}$ count at $6 \mathrm{~h}) /(\mathrm{CFU}$ count at $1 \mathrm{~h})] \times 100 \%$.

\section{Isolation of RNA and Quantitative Real-Time PCR (qRT-PCR)}

Total RNA was extracted from cultured cells using the RNeasy kit (Qiagen, Cat. \# 217004) in accordance with the manufacturer's instructions. cDNA was synthesized from 0.5-1.0 $\mu \mathrm{g}$ total RNA using Superscript II Reverse Transcriptase (Invitrogen, Cat. \# 18080044). Then, qRT-PCR was performed in triplicate with the ABI PRISM 7900HT sequence detection system (ABI) using SYBR green (Genecopoeia, Cat. \# QP005). Relative mRNA levels were calculated and normalized to $18 \mathrm{~S}$ rRNA. The primers were used as follows: CD5L forward 5'-TTGGAGAACAACTGTACCCATGGC-3', reverse 5'-AGGCTGAGGGAAAGGTGTCTAAAG-3'; Bcl2alb forward 5'-GTTTCCAGTTTTGTGGCAGA-3', reverse 5'CCCAGAACTGTCCTGTCATC-3'; MRPS18C forward 5'-GCATTTATGGAAGGCACATAAC-3', reverse 5'-TGG CAGGAACTTCACAAATAC-3'; $18 \mathrm{~S}$ rRNA forward 5'GCAATTATTCCCCATGAACG-3', reverse 5'-GGCCTCA CTAAACCATCCAA-3'. Directional polyA RNA-sequencing was performed by the Genomics, Epigenomics, and Sequencing Core (GESC) at the University of Cincinnati.

\section{Immunofluorescence Staining}

BMDMs treated with $\mathrm{rGDF} 3(20 \mathrm{ng} / \mathrm{mL})$ and GW3965 (1 $\mu \mathrm{mol} / \mathrm{L}$ ) (DMSO used as control) were fixed on the coverslip, blocked with $1 \%$ BSA, $0.3 \%$ Triton X-100, 0.1\% Tween 20 and incubated with primary antibody $(\mathrm{LXR} \alpha$, Invitrogen, Cat. \# PA1-330) diluted in 1\% BSA, $0.1 \%$ Tween 20 overnight at $4{ }^{\circ} \mathrm{C}$. After washing, BMDMs were incubated with secondary antibody at RT for $1 \mathrm{~h}$. Thereafter, cells were washed three times with PBS and mounted with ProLong diamond Antifade Mounting medium with DAPI (Invitrogen, Cat. \# P36962). Images were captured with Zeiss LSM710 LIVE
Duo Confocal Microscope (Live Microscopy Core, University of Cincinnati).

\section{Statistical Analysis}

Statistical calculations were performed with GraphPad Prism 7.0 software (GraphPad Software, Inc., USA). The experimental data were expressed as mean \pm SEM. Differences between two groups were analyzed using unpaired two-tailed t-test and survival rates were analyzed using log rank test. $p<0.05$ was considered to be statistically significant.

\section{RESULTS}

\section{Administration of rGDF3 Attenuates Polymicrobial Sepsis-Induced Mortality and Organ Injury in Mice}

Our recent work showed that rGDF3 suppressed inflammatory response and improved cardiac function and survival in endotoxin-induced sterile inflammation mouse model. To explore whether rGDF3 could provide a preventive effect in response to polymicrobial sepsis, WT mice were received rGDF3 (20 $\mu \mathrm{g} / \mathrm{kg}$ body weight) or BSA vesicle via the tail vein injection $3 \mathrm{~h}$ prior to CLP surgery (Figure 1A), and then mortality was monitored over 7 days. We observed that rGDF3-treated mice exhibited significantly higher survival rate than BSA-treated mice over a period of 7 days post-CLP (Figure 1B). Median survival was $76 \mathrm{~h}$ in rGDF3-treated group and $41 \mathrm{~h}$ in BSA-treated group (Figure 1B, $p<0.05$ ). Next, we assessed organ injury in BSAand rGDF3-treated mice at $24 \mathrm{~h}$ post-CLP by: (1) conducting histopathological analysis, (2) determining tissue edema, and (3) measuring biomarkers of organ damages in the serum. Firstly, we found that the administration of rGDF3 significantly rescued CLP-induced lung injury, as evidenced by the decrease in neutrophil infiltration, formation of hyaline membranes, thickness of alveolar wall, and the alveolar collapse in lung tissues collected from rGDF3-treated mice (injury score $0.264 \pm$ 0.025 ), compared to those from BSA-treated mice (injury score $0.452 \pm 0.034$ ) (Figures 1C-E). In addition, rGDF3-treated mice exhibited lower ratio of wet weight/dry weight than that from BSA-treated mice ( $4.325 \pm 0.089$ vs. $4.558 \pm 0.047)$ (Figure 1F). Similar results were observed for the wet weight/dry weight ratio of the spleen (4.462 \pm 0.041 vs. $4.639 \pm 0.069)$ (Figure 1G). Furthermore, we tested serum levels of alanine transaminase (ALT) and creatinine (Cr), biomarkers of liver injury and kidney damage, respectively. As shown in Figure 1H, I, the concentrations of both biomarkers were significantly lower in rGDF3-treated mice, compared to BSA-treated mice at $24 \mathrm{~h}$ postCLP. Collectively, these data indicate that pre-administration of rGDF3 significantly decreases CLP-induced multi-organ injury in mice.

\section{Administration of rGDF3 Decreases Bacterial Burden and Cytokine Levels in Response to CLP}

Since bacterial burden and inflammatory responses are important driving factors for the pathogenesis and progression 


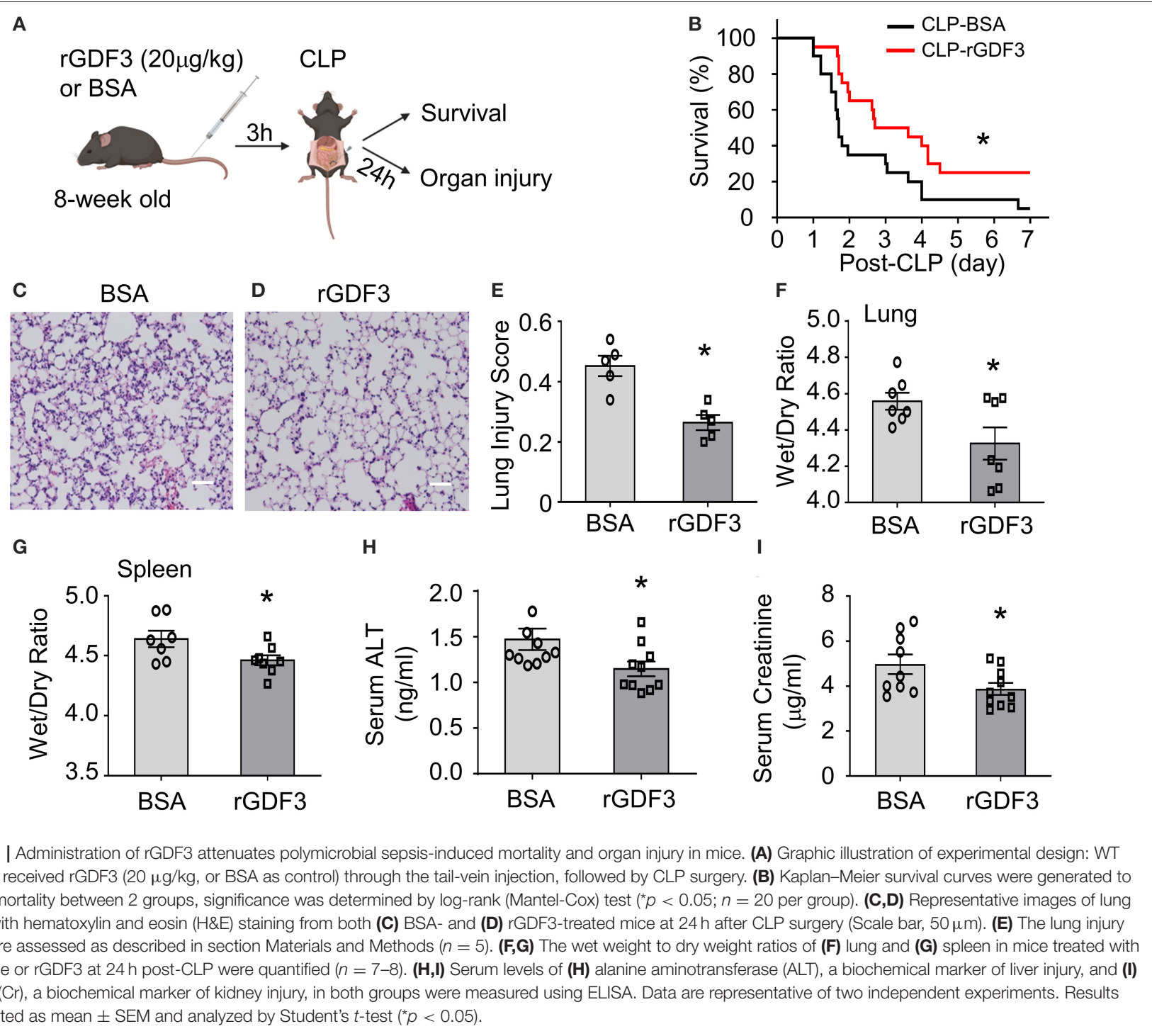

of sepsis $(1,6,7)$, we next sought to determine the effects of rGDF3 on these aspects. The bacterial burdens in the blood and PLF were examined at $20 \mathrm{~h}$ post-CLP surgery. As shown in Figures $\mathbf{2 A}, \mathbf{B}$, the rGDF3-treated group presented significantly lower bacterial load in blood and PLF compared to control group (BSA-treated). Representative images for CFUs in both blood and PLF were shown in Figures 2C,D. In parallel, results from ELISA analysis showed that the levels of inflammatory cytokines IL6 and TNF- $\alpha$ were significantly suppressed by rGDF3 administration in both sera (Figures 2E,F) and PLFs (Figures 2G,H). Together, these results suggest that the beneficial effects of rGDF3 on survival and organ damage may be associated with its ability to control bacterial burden and inflammatory responses.

\section{rGDF3 Treatment Promotes Phagocytic} and Bactericidal Activities of Macrophages

Considering that macrophages play an essential role in bacterial clearance during polymicrobial sepsis (12), we next conducted bacterial phagocytosis and intracellular killing assays in three different sources of macrophages: (1) RAW264.7 cell line, (2) BMDMs, and (3) PMs isolated from WT mice. Firstly, we investigated the effect of rGDF3 on the cell viability with MTS assay. As shown in Supplementary Figures 1A,B, stimulation with different rGDF3 doses $(10,20,50 \mathrm{ng} / \mathrm{mL})$ did not affect the viability of BMDMs and RAW264.7 cells. Next, using the fluorescence-conjugated E. coli BioParticles, we found that treatment of macrophages with rGDF3 at doses of 20 and $50 \mathrm{ng} / \mathrm{mL}$ greatly increased the uptake of $E$. coli BioParticles in both BMDMs (Figure 3A) and RAW264.7 cells 
A

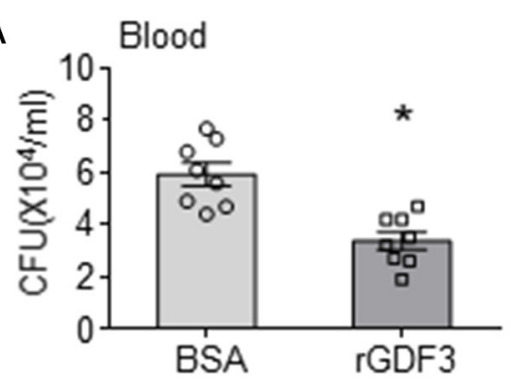

B

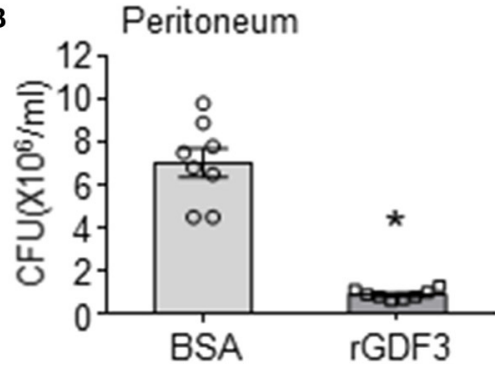

E
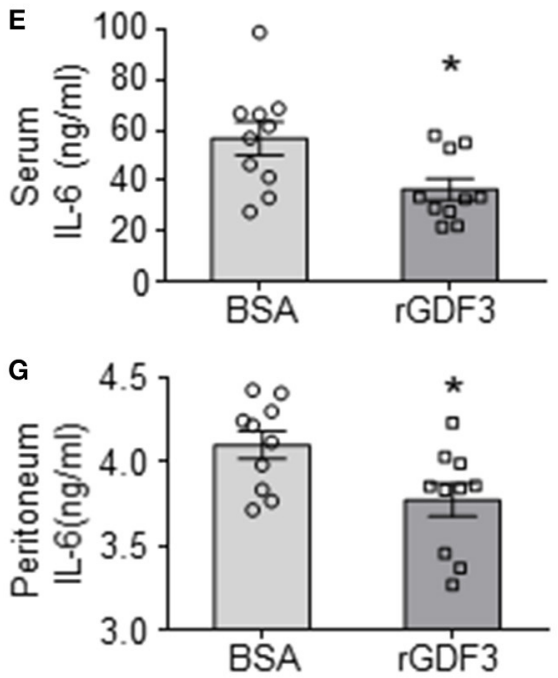

c

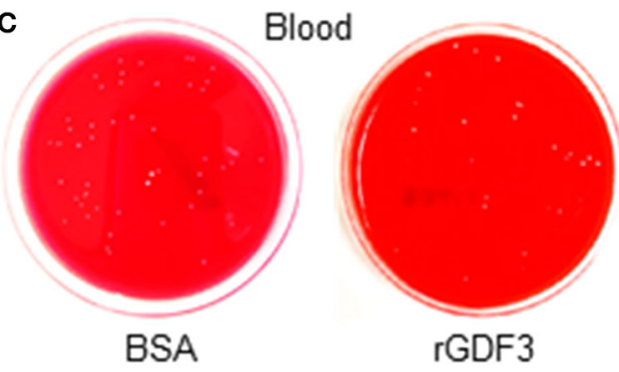

D

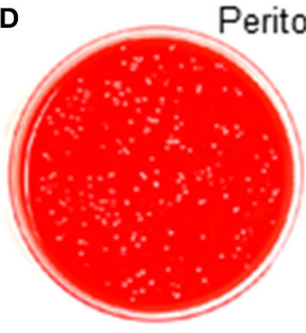

BSA

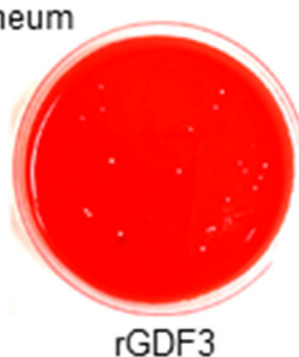

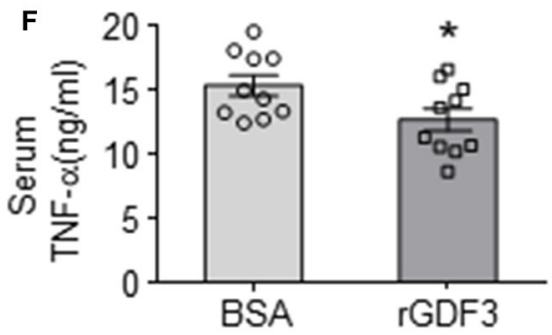

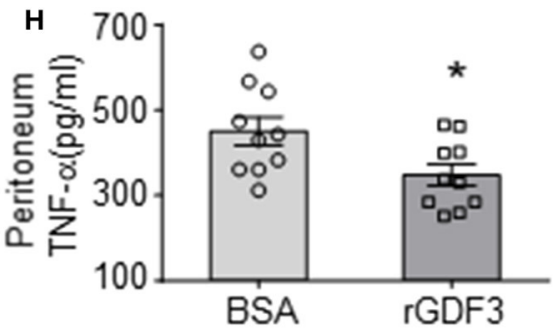

FIGURE 2 | Administration of rGDF3 decreases bacterial burden and cytokine levels in response to CLP. (A-D) The bacterial burden in both blood (A, C) and PLF (B, D) were compared between BSA- and rGDF3-treated mice at $20 \mathrm{~h}$ after CLP surgery. (E-H) Cytokine levels in serum [(E): IL-6, (F): TNF- $\alpha]$ and PLF [(G): IL-6, (H): TNF- $\alpha$ ] in mice were measured at $20 \mathrm{~h}$ after CLP surgery using ELISA assays ( $n=9-10$ per group). CFU, colony-forming unit. Data are representative of two independent experiments. All results are presented as mean \pm SEM and analyzed by Student's $t$-test $\left({ }^{*} p<0.05\right)$.

(Figure 3B). Of interest, rGDF3 at a lower dose $(10 \mathrm{ng} / \mathrm{mL})$ significantly enhanced phagocytosis of E. coli BioParticles in RAW264.7 macrophages but not BMDMs (Figure 3B). To further validate these results, the uptake of fluorescenceconjugated E. coli BioParticles was examined under confocal microscopy. We found that the intensity of red particles in rGDF3-treated BMDMs was significantly higher than that in control BSA-treated cells (Figures 3C,D). Similar findings were also observed in rGDF3-treated RAW264.7 cells (Figures 3E,F). In addition, flow cytometry analysis results further showed that rGDF3-treated PMs displayed higher content of red fluorescence (Figures 3G,H). Thus, these data generated from all three different analysis methods consistently indicate that rGDF3 is able to augment macrophage phagocytosis. Lastly, we assessed the phagocytic and bactericidal activities of BMDMs and RAW264.7 cells using live E. coli, as described in Figure 4A. We found that rGDF3 treatment significantly increased the bacterial uptake by 2.64 -fold in BMDMs (Figure 4B) when compared to BSA-treated cells. The numbers of bacteria remained in BMDMs at $6 \mathrm{~h}$ after intracellular killing were shown in Figure 4C. Remarkably, rGDF3 stimulation could boost intracellular killing activity by $26.59 \%$ in BMDMs, compared to BSA-treated controls (Figure 4D). Similar findings were also observed 


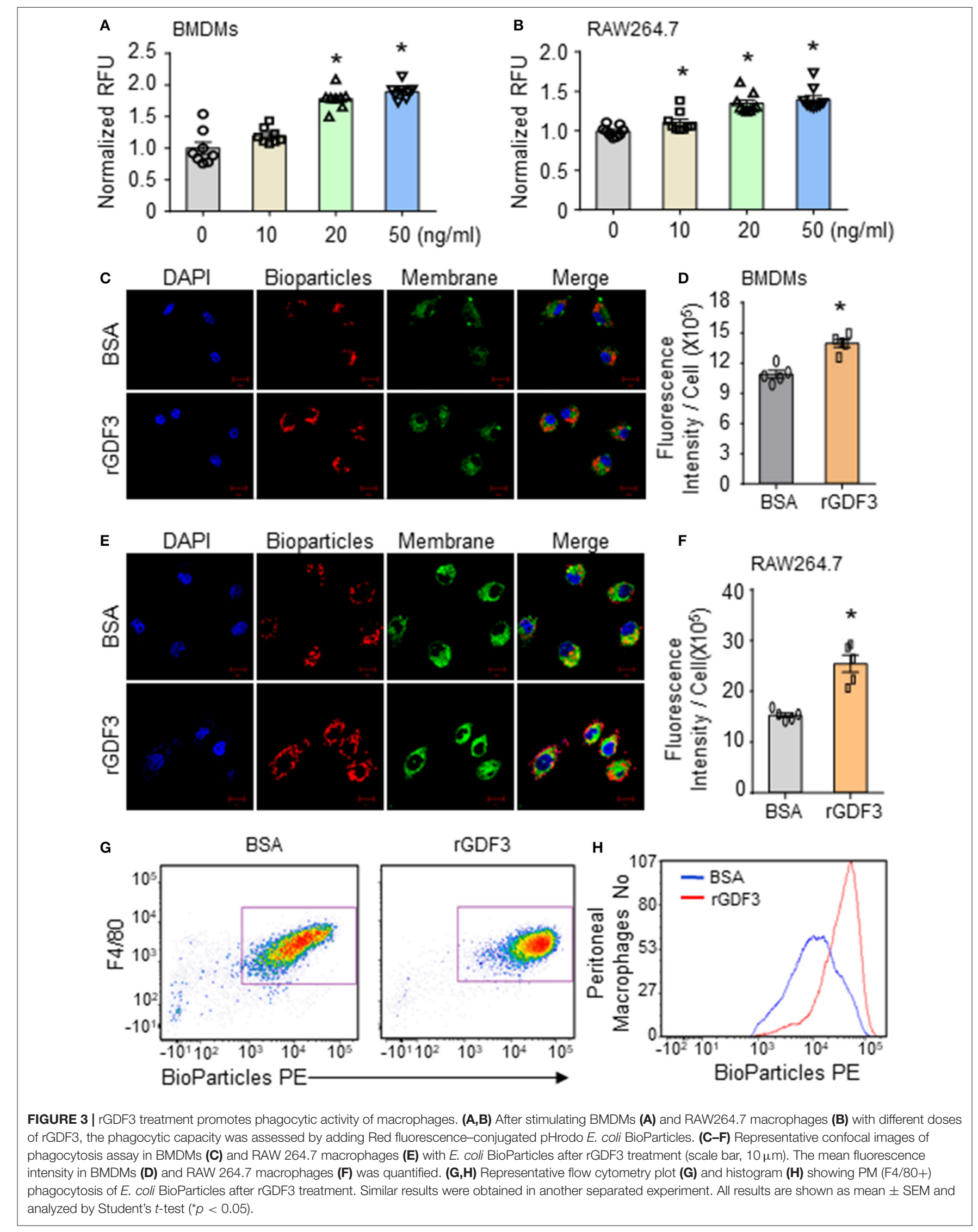




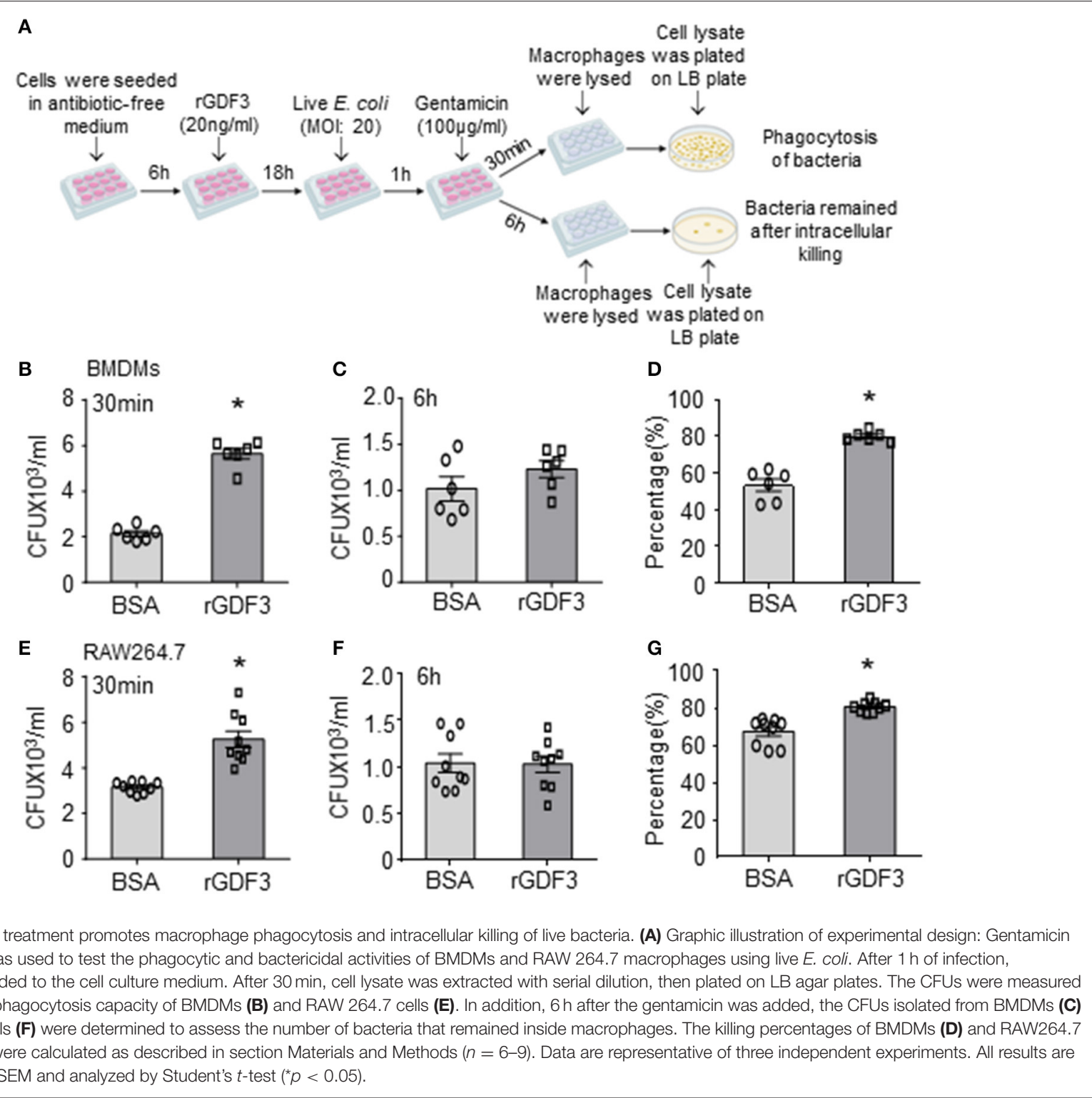

in rGDF3-treated RAW264.7 cells, in which the uptake of bacteria and intracellular killing activity were significantly increased, compared to BSA-treated cells (Figures 4E-G). Taken together, these data indicate that treatment of macrophages with rGDF3 could improve phagocytosis and bactericidal activities.

\section{RNA Sequencing Analysis of Gene Expression Profile in BMDMs Treated With rGDF3}

To identify potential mechanisms underlying the effect of rGDF3 in promoting macrophage phagocytosis of bacteria, we treated BMDMs with $\mathrm{rGDF} 3(20 \mathrm{ng} / \mathrm{mL})$ or control BSA for $18 \mathrm{~h}$, followed by isolation of total RNAs for RNA sequencing (RNAseq). Unexpectedly, we identified only 6 differentially expressed genes, of which 4 were significantly upregulated and 2 were down-regulated $(p<0.05)$, as listed in Supplementary Table 1 and illustrated in Figure 5A. Of interest, among these 4 upregulated genes, $\mathrm{CD} 5 \mathrm{~L}$ has been recently reported to stimulate the phagocytosis of bacteria in macrophages (32). CD5L, also referred to as apoptosis inhibitor 6 (Api6) or apoptosis inhibitor of macrophages (AIMs), is a soluble protein mainly produced by macrophages $(32,33)$. Importantly, the expression of CD5L is controlled by the activation of LXR $\alpha$ in macrophages (33). Indeed, another LXR $\alpha$-controlled gene, Bcl2alb (34), was also significantly upregulated in rGDF3-treated macrophages (Figure 5B). Therefore, we speculated that rGDF3 might enhance macrophage phagocytosis through activating LXR $\alpha$ pathway. To test this hypothesis, we treated BMDMs with GW3965, a potent LXR $\alpha$ agonist, followed by measuring the expression levels of CD5L and Bcl2a1b. qRT-PCR results showed that 


\section{A}

BSA rGDF3

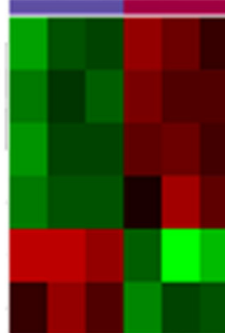

MRPS18C

Usmg5

Bcl2a1b

CD5L

E030030106Rik

SIc13a3

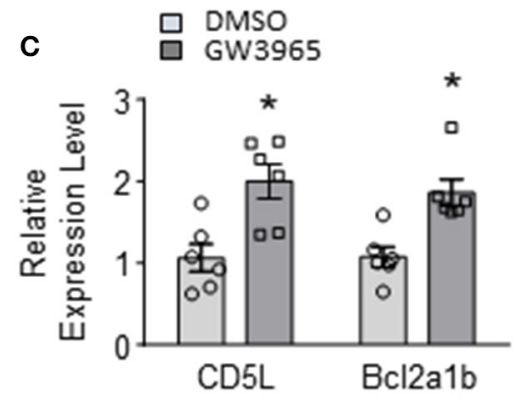

E

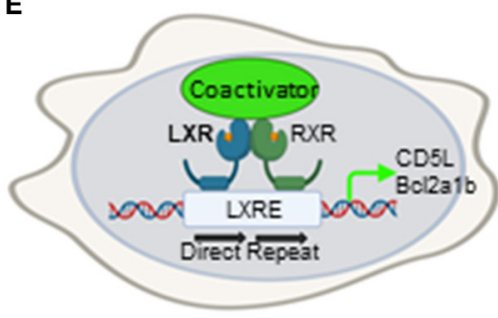

G

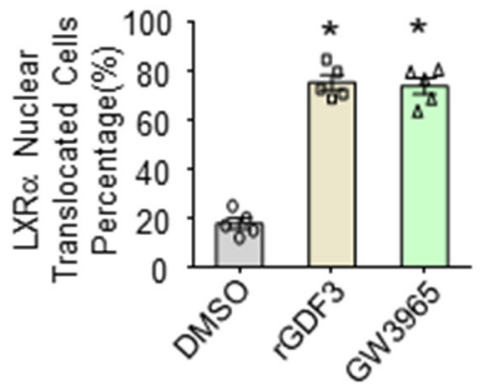

B

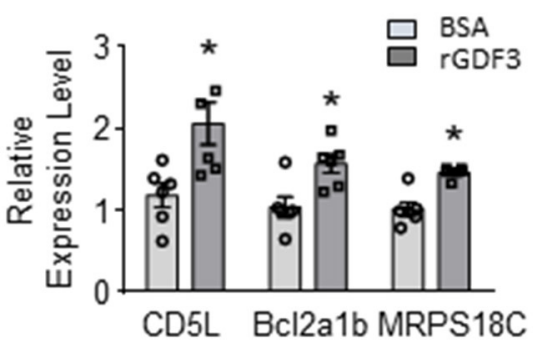

D $\quad$ 吕 $\mathrm{GMSO} 2033$
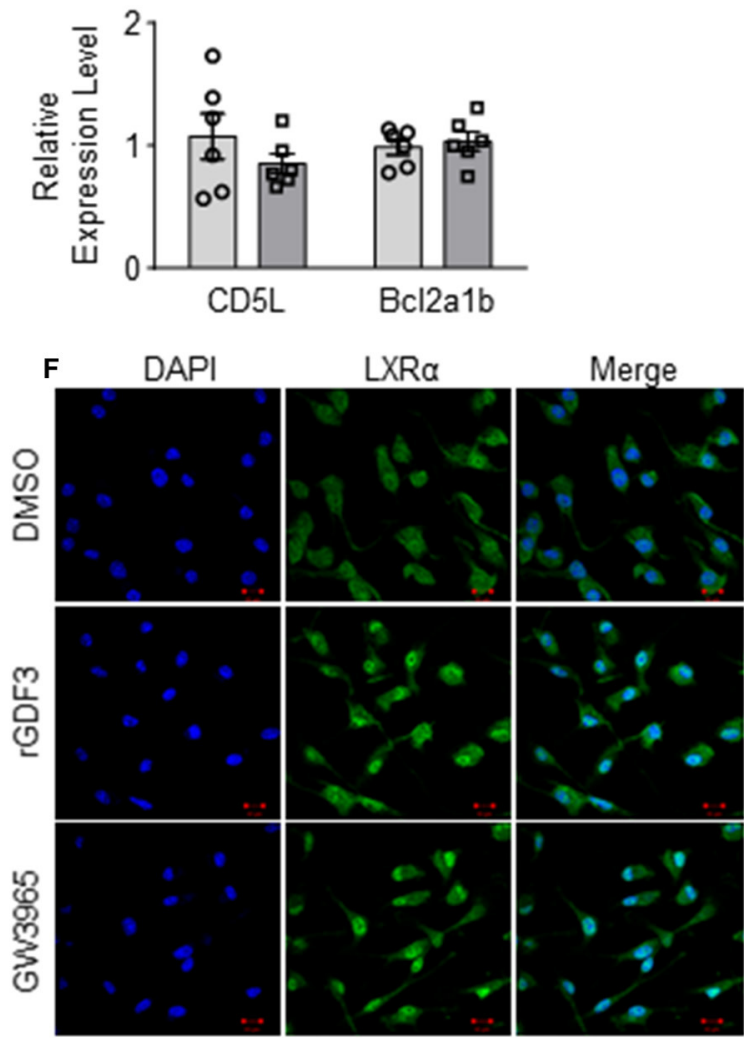

FIGURE 5 | Gene expression profile in BMDMs treated with rGDF3 by high-throughput RNA sequencing. (A) Heatmap of the differentially expressed genes from BMDMs treated with BSA or rGDF3 $(20 \mathrm{ng} / \mathrm{mL})(n=3)$. (B) The altered expression of CD5L, Bcl2a1b, and MRPS18C gene in rGDF3-treated BMDMs was validated by qRT-PCR $(n=6)$. (C) Expression of CD5L and Bcl2a1b in GW3965 (1 $\mu$ mol/L)-treated BMDMs was determined by qRT-PCR ( $n=6)$ at $18 \mathrm{~h}$ post-treatment. (D) Expression of CD5L and Bcl2a1b in BMDMs were measured at 18 h post-GSK2033 (2 $\mu \mathrm{mol} / \mathrm{L})$ treatment $(n=6)$. (E) Graphic scheme of the LXR $\alpha$-CD5L signal cascade in macrophages. Representative images (F) and quantification (G) of immunofluorescence staining for LXR $(\mathrm{green})$ in $B M D M s$ at $18 \mathrm{~h}$ after rGDF3 $(20 \mathrm{ng} / \mathrm{mL})$ or GW3965 (1 $\mu \mathrm{mol} / \mathrm{L})$ treatment (Scale bar, $10 \mu \mathrm{m} ; n=5)$. Data are representative of two $(\mathbf{B}-\mathbf{D}, \mathbf{F}, \mathbf{G})$ independent experiments. All results are shown as mean \pm SEM and analyzed by Student's $t$-test $\left({ }^{*} p<0.05\right)$.

activation of LXR $\alpha$ by its agonist significantly increased mRNA levels of CD5L and Bcl2a1b, compared with control-treated macrophages (Figure 5C). In contrast, blockade of LXR $\alpha$ in BMDMs by its antagonist, GSK2033, offset rGDF3-mediated upregulation of CD5L and $\mathrm{Bcl} 2 \mathrm{a} 1 \mathrm{~b}$ (Figure 5D). Given that the activation of $\operatorname{LXR} \alpha$ is associated with its translocation to the nucleus $(35,36)$, as indicated in Figure 5E, we next determined whether rGDF3 could mimic the effect of $\operatorname{LXR} \alpha$ agonist GW3965 on LXR $\alpha$ translocation, using immunofluorescence staining. We observed that the number of macrophages with nuclear translocation of $\mathrm{LXR} \alpha$ was similar between rGDF3and GW3965-treated groups (Figures 5F,G). Put together, these results demonstrate that $\mathrm{rGDF} 3$ could activate $\mathrm{LXR} \alpha$ pathway in macrophages. 


\section{Inhibition or Deficiency of LXR $\alpha$ Abolishes rGDF3-Mediated Effects on Macrophage Phagocytosis and Bacterial Killing Activities}

Next, we determined whether the activation of LXR $\alpha$ is responsible for rGDF3-mediated increase of bacterial clearance by macrophages. To this end, we pre-treated BMDMs with LXR $\alpha$ antagonist, GSK2033, followed by addition of rGDF3 $(20 \mathrm{ng} / \mathrm{mL})$. LXR $\alpha$ agonist (GW3965, $1 \mu \mathrm{mol} / \mathrm{L}$ ) and rGDF3 alone were used as controls. Subsequently, phagocytosis of E. coli BioParticles was analyzed. We observed that treatment with both LXR $\alpha$ agonist and rGDF3 alone could significantly enhance BMDMs phagocytosis of E. coli BioParticles (Figure 6A). However, rGDF3 failed to improve phagocytosis of E. coli BioParticles in BMDMs pretreated with GSK2033 (Figure 6A). These results were also validated with confocal microscopy, as shown in Figures 6B,C that the intensity of red fluorescence in GW3965- and rGDF3treated macrophages was significantly higher than in DMSOtreated cells. Meanwhile, the effects of rGDF3 on phagocytosis of E. coli BioParticles were blunted when BMDMs were pre-treated with LXR antagonist GSK2033, showing similar fluorescence intensity to the DMSO group (Figures 6B,C). Lastly, we isolated BMDMs from LXR $\alpha-\mathrm{KO}$ mice (Figure 6D) and assessed CD5L expression by qRT-PCR after the treatment of BSA or rGDF3. As expected, rGDF3-treatment failed to increase the expression levels of CD5L in LXR $\alpha$-KO BMDMs (Figure 6E). Furthermore, while treatment of $\mathrm{LXR} \alpha-\mathrm{KO}$ BMDMs with rGDF3 did not improve phagocytosis, loss of LXR $\alpha$ in macrophages significantly reduced the uptake of $E$. coli BioParticles under basal conditions (Figure 6F). Using living bacteria, we also observed that rGDF3mediated enhancement of bacterial entry and intracellular killing was offset by knockout of LXR $\alpha$ (Figures 6G-I). Please note here that the entry of living bacteria into BSA-treated LXR $\alpha$-KO cells (Figure 6G) appeared similar as BSA-treated WT cells presented in Figure 4B. This discrepancy may be ascribed to different batch of living bacteria. Indeed, higher number of living bacteria remained in LXR $\alpha-\mathrm{KO}$ cells (Figure 6H), compared to WTcells (Figure 4C). Accordingly, the percentage of intracellular killing in LXR $\alpha$-KO cells (43\%, Figure 6I) was lower than WTcells (54\%, Figure 4D) under basal conditions. Collectively, these results indicate that the activation of LXR $\alpha$ pathway is essential for rGDF3 to stimulate macrophages phagocytosis and killing of bacteria.

\section{Therapeutic Effects of rGDF3 in WT Mice Upon CLP Surgery}

To further determine whether rGDF3 had any therapeutic effects in vivo against polymicrobial sepsis, we injected WT mice with a single dose of rGDF3 $(100 \mu \mathrm{g} / \mathrm{kg})$ or BSA vehicle at $1 \mathrm{~h}$ post-CLP surgery, followed by a series of experiments for the analysis of bacterial burden, cytokine levels, organ injury and mortality. We observed that post-administration of rGDF3 into CLP-mice significantly reduced bacterial burdens in the blood (Figure 7A) and PLF (Figure 7D) to a greater degree, compared to BSA-treated control mice. In addition, we found that the pro-inflammatory cytokines (i.e., IL- 6 and TNF- $\alpha$ ) levels in both serum (Figures 7B,C) and PLF (Figures 7E,F) were significantly lower in rGDF3-treated mice than controls. Furthermore, the ratios of wet/dry weight in lungs (Figure 7G) and spleens (Figure 7H) collected from rGDF3-treated CLPmice were significantly reduced, compared to those samples from BSA-treated controls. Lastly, post-administration of rGDF3 into CLP-mice significantly improved survival outcome, as evidenced by $31.25 \%$ of rGDF3-treated mice $(n=16)$ survived at day 7 postCLP, when only $6.25 \%$ of BSA-treated mice survived $(n=16)$. Meanwhile, the median survival was longer in rGDF3-treated mice than that in BSA-treated group (104 vs. $59 \mathrm{~h}$ ) (Figure 7I, $p<$ $0.05)$. Collectively, these data indicate that post-administration of rGDF3 could increase bacterial clearance, reduce inflammatory response, attenuate organ injury and improve animal survival in CLP-induced septic mice.

\section{DISCUSSION}

It is well-recognized that impaired macrophage phagocytosis and intracellular killing of bacteria is the major culprit for insufficient antibacterial defense and hyper-inflammation in septic patients (37). In the present study, we showed that rGDF3 was able to increase bacteria uptake and killing by macrophages through activating LXR $\alpha$ pathway (Figure 8). Furthermore, either pre- or post-administration of rGDF3 significantly decreased polymicrobial sepsis-induced mortality in mice. This preferable outcome was associated with greatly reductions in systemic and local bacterial burden, inflammatory responses and multiple organ injury in CLP mice.

As one of the most important innate immune defenses, the phagocytosis and internal killing of pathogens by phagocytic cells is the first-line defense during infection due to its immediate response to pathogens. In patients, the reduced phagocytic activity during the first $24 \mathrm{~h}$ after admission has been identified as a positive predictor for mortality (38). Therefore, as "rapid response team," macrophages are vital to host defense against microorganisms due to their ability in internalizing and digesting bacteria. Consistently, recent studies demonstrate that tissueresident macrophages prevented neutrophil influx, neutrophilmediated monocyte infiltration and inflammatory damage through prostrating their membranes to cloaking the minor tissue damage (39). Furthermore, we and others recently showed that enhancing the phagocytosis and bacterial killing activity of macrophage could improve animal survival in response to the polymicrobial sepsis $(11,40,41)$. Along this line, our present study defined rGDF3 as a novel protector for enhanced clearance of bacteria by macrophages, leading to higher survival rate in response to the polymicrobial sepsis.

GDF3 was initially identified as a member of TGF- $\beta$ superfamily to function in the early embryonic development $(16-18)$. Prior work has shown that TGF- $\beta$ signaling involved alternatively activation of macrophages (42). Our recent study demonstrated that patients with sepsis exhibited significantly higher levels of serum GDF3 as a compensatory mechanism in response to septic shock (26), suggesting the potential role of GDF3 in treating sepsis. In line with these findings, we 
A

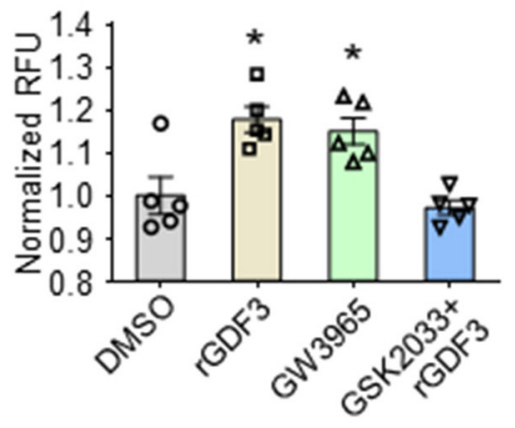

C

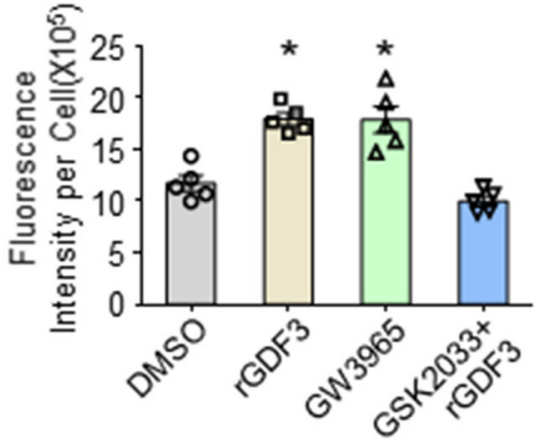

B DAPI
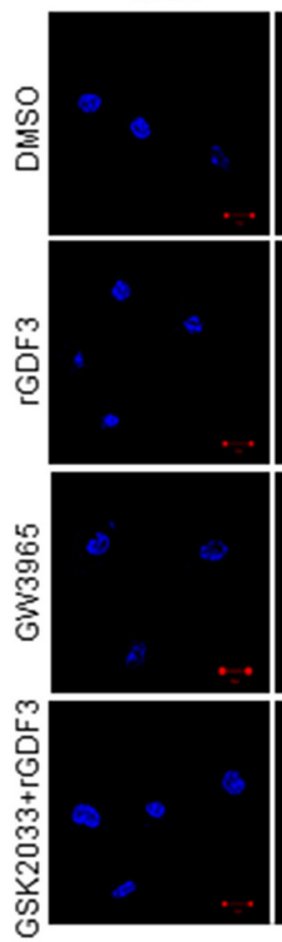

Bioparticles or live $E$. coli
D

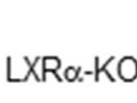

$$
\begin{array}{r}
\text { Femur and } \\
\text { bones }
\end{array}
$$

Change medium on day 4

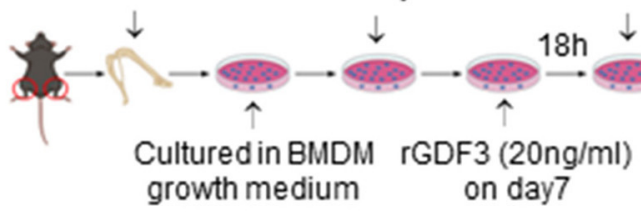

$\mathbf{F}$

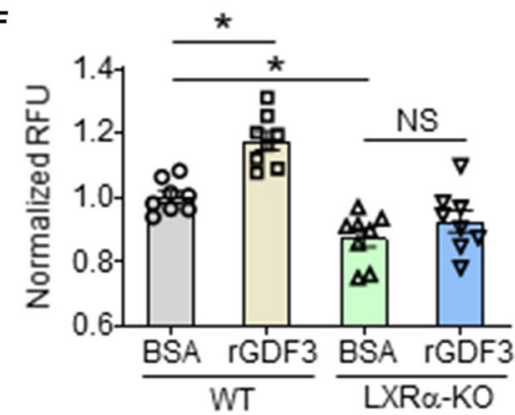

G

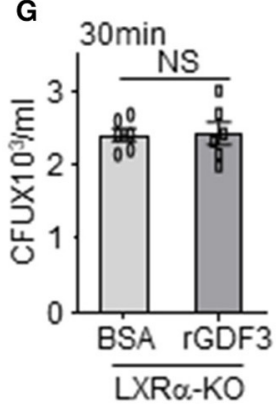

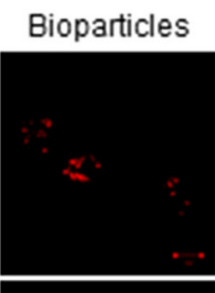
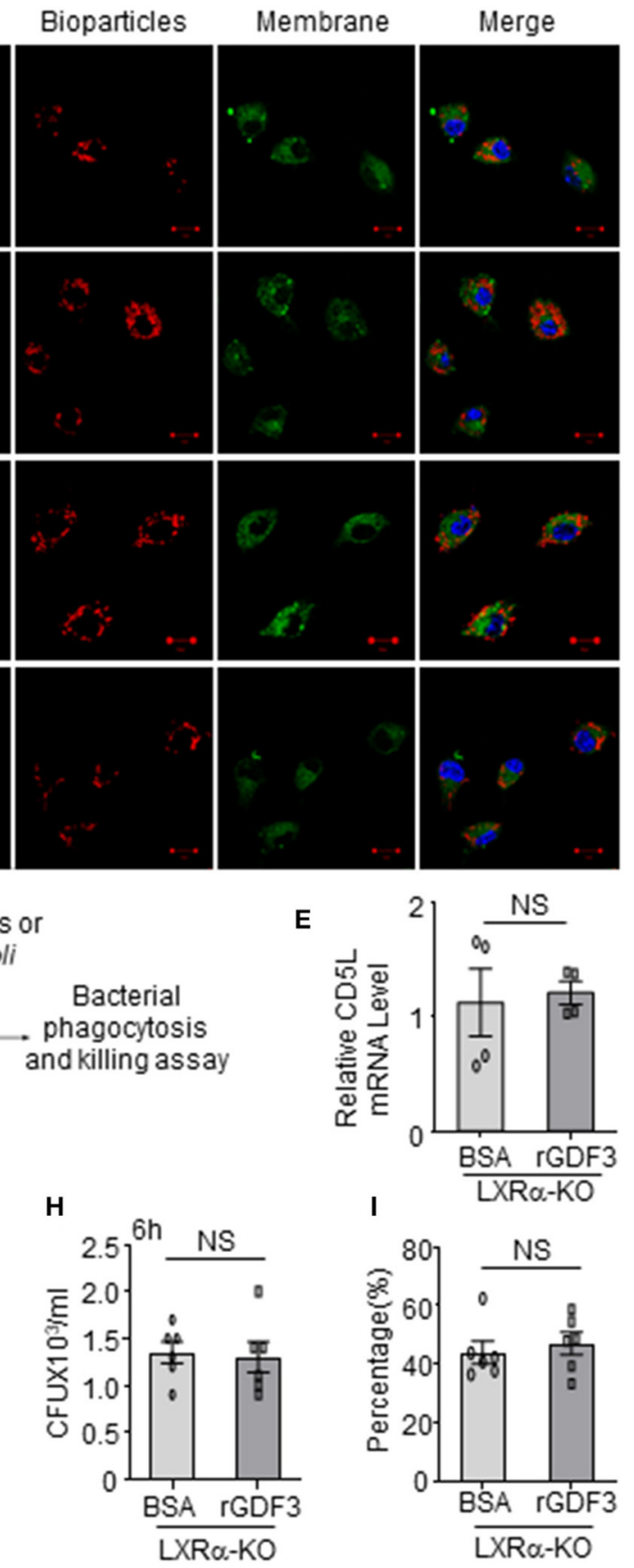

H

\section{Bacterial} phagocytosis and killing assay

LXR $\alpha-K O$
I

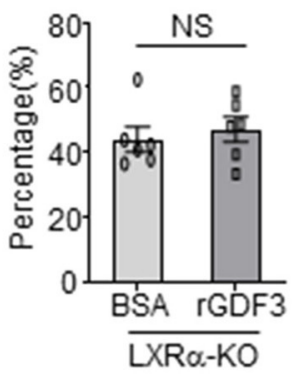

FIGURE 6 | Inhibition or deficiency of LXR $\alpha$ abolishes rGDF3-mediated effects on macrophage phagocytosis and bacterial killing activities. (A) BMDMs were treated with DMSO (0.005\%, vesicle control), rGDF3, GW3965, and GSK2033+rGDF3 for 18h, then phagocytic capacity was assessed using red $E$. coli BioParticles. (B) Representative confocal images of phagocytosis assay in BMDMs treated with DMSO, rGDF3, GW3965, and GSK2033 + rGDF3 with red E. coli BioParticles (Scale bar, $10 \mu \mathrm{m}$ ), and (C) their quantifications of the mean fluorescence intensity in each group. (D) Graphic scheme of experimental design for BMDMs isolated from LXR $\alpha-K O$ mice and following treatment. (E) The altered expression of CD5L gene in rGDF3-treated BMDMs isolated from LXR $\alpha$-KO mice was validated by qRT-PCR $(n=4)$. (F) Phagocytic capacity of WT- and LXR $\alpha$-KO-BMDMs after rGDF3 treatment was assessed by adding E. coli BioParticles. (G-I) Gentamicin protection assay was used to test the phagocytic and bactericidal activities of WT- and LXR $\alpha-K O-B M D M s$. (G) The CFUs were measured as an indicator for phagocytosis capacity of BMDMs. (H) $6 \mathrm{~h}$ after the gentamicin was added, the bacterial residue remained inside macrophages were assessed. (I) The killing percentages of LXR $\alpha-K O$ BMDMs were calculated $(n=6)$. Similar results were obtained in other two independent experiments. All results are shown as mean \pm SEM and analyzed by Student's $t$-test $\left({ }^{*} p<0.05\right)$. 

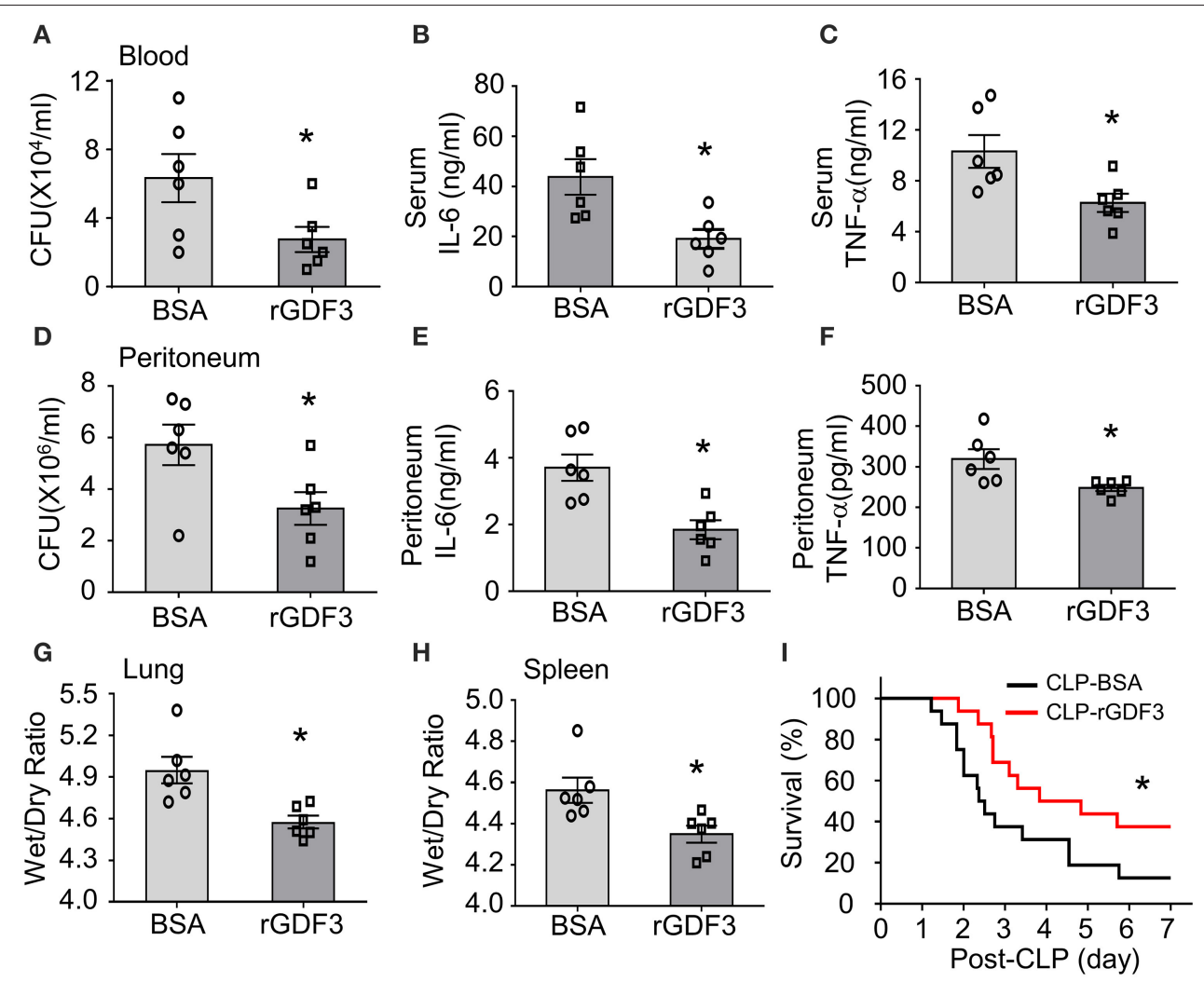

FIGURE 7 | Therapeutic effects of rGDF3 in WT mice upon CLP surgery. A single dose of rGDF3 (100 $\mu \mathrm{g} / \mathrm{kg})$ or BSA vehicle was injected at $1 \mathrm{~h}$ post-CLP. (A) The bacterial burden in blood was compared between BSA- and rGDF3-treated mice at $24 \mathrm{~h}$ after CLP surgery. (B,C) Cytokine levels in sera [(B): IL-6, (C): TNF- $\alpha$ ] of BSAand rGDF3-treated mice were measured at $24 \mathrm{~h}$ post-CLP surgery using ELISA kits $(n=6)$. (D) The bacterial burden in PLF was compared between BSA- and rGDF3-treated mice at $24 \mathrm{~h}$ post-CLP surgery. (E,F) Cytokine levels in PLF [(E): IL-6, (F): TNF- $\alpha$ ] of BSA- and rGDF3-treated mice were measured at 24 h post-CLP surgery $(n=6)$. (G,H) The wet weight to dry weight ratios of lung $\mathbf{( G )}$ and spleen $\mathbf{( H )}$ in BSA-and rGDF3-treated mice at $24 \mathrm{~h}$ post-CLP were quantified $(n=6)$. Similar results were obtained in another separated experiment. All results are presented as mean \pm SEM and analyzed by Student's $t$-test ( $\left.{ }^{*} p<0.05\right)$. (I) Kaplan-Meier survival curves were generated to compare mortality between two groups, significance was determined by log-rank (Mantel-Cox) test ( $\left.{ }^{*} p<0.05 ; n=16\right)$.

observed that rGDF3 treatment could enhance phagocytosis and killing of bacteria in different kinds of macrophages, including BMDMs, RAW264.7 macrophages, and PMs. Furthermore, using a clinical-relevant polymicrobial sepsis model, we found that the administration of rGDF3 either before or after CLP surgery was able to improve survival and suppress inflammatory responses, which was associated with the reduced organ injuries.

The Liver X Receptors ( $\operatorname{LXR} \alpha$ and $\operatorname{LXR} \beta$ ) belong to nuclear receptors that regulate transcription of genes for cholesterol metabolism, cholesterol transport, and lipogenesis (43). Unlike $\operatorname{LXR} \beta$ that is ubiquitously expressed, LXR $\alpha$ is dominantly expressed in liver and macrophages $(44,45)$. Interestingly, the present study identified that rGDF3 markedly stimulated the nuclear translocation of $\operatorname{LXR} \alpha$ in macrophages. It is important to note here that previous studies implicated the essential role of LXR pathway for the expression of genes directly involved in antimicrobial responses, such as $\mathrm{CD} 5 \mathrm{~L}$, which was reported to stimulate macrophage phagocytosis of bacteria $(32,33)$. In addition, LXR-deficient mouse models are more susceptible to bacterial-induced illness, and pharmacological treatment with LXR agonist improved clinical signs associated with bacterial infection (46). In line with these reports, the present study revealed that rGDF3 treatment significantly upregulated CD5L expression in macrophages and augmented macrophage phagocytosis. By contrast, the pretreatment of macrophages with LXR $\alpha$ antagonist (GSK2033) abolished the effects of rGDF3 on the expression of CD5L and macrophage phagocytosis. Consistently, our ex vivo results also showed that rGDF3 treatment failed to enhance phagocytosis and bacterial killing activities of BMDMs isolated from LXR $\alpha-\mathrm{KO}$ mice. These results suggest that rGDF3-mediated macrophage phagocytosis is dependent on the activation of $\operatorname{LXR} \alpha$. Nonetheless, future studies should focus on the detailed mechanisms behind the interaction of rGDF3 and LXR $\alpha$.

At present, CD5L has been well-studied in the regulation of antimicrobial response $(32,33,47-52)$. CD5L is a macrophagederived soluble protein belonging to the scavenger receptor cysteine-rich domain superfamily (SRCR-SF) (47). Like other SRCR-SF members (e.g., MARCO, SR-AI), CD5L exhibits pattern recognition and physically interacts with Gram-negative and -positive bacteria via directly binding to 


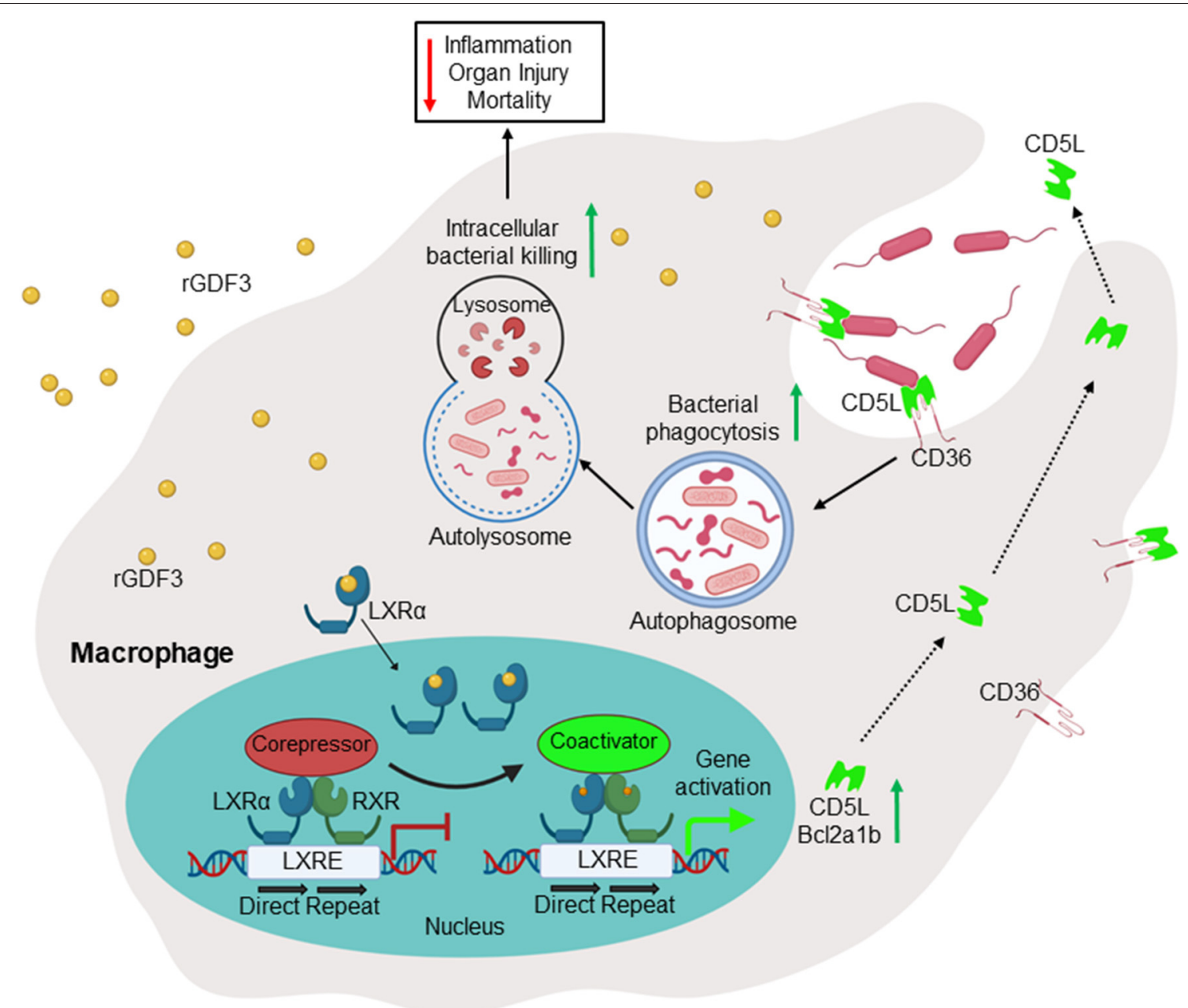

FIGURE 8 | Scheme depicting that administration of GDF3 into septic mice improves survival via enhancing macrophage phagocytosis, which is mediated by activation of the $\mathrm{LXR} \alpha-\mathrm{CD} 5 \mathrm{~L}$ pathway.

LPS, LTA, or peptidoglycan (48). More interestingly, recent studies further showed that CD5L could be transported into early endosomes and internalized by macrophages through CD36, a bona fide cell-surface receptor for CD5L (47, 48). Importantly, CD36 also recognizes bacterial cell-wall components and involves phagocytosis (49). In addition, the complex of CD5L/CD36 is a strong autophagy inducer in macrophages that may enhance intracellular killing of bacteria through autolysosomes (50-52). Therefore, the mechanism underlying rGDF3-induced phagocytosis could be through the activation of $L X R \alpha$, leading to increased CD5L generation and consequently, CD5L works together with CD36 to recruit bacteria for phagocytosis (Figure 8). Given that a subset of small GTP-binding proteins (e.g., Rap1, Arf6, Rho) are well-known to control and coordinate the successive steps of the bacterial phagocytic process by macrophages (53-55), future investigations would be needed to address whether there is any crosstalk between the GDF3-LXR $\alpha-C D 5 L$ axis and the small GTP-binding proteins in the phagocytosis of bacteria by macrophages.

\section{CONCLUSIONS}

Our data presented in this study for the first time demonstrate that, through activating the LXR $\alpha$-CD5L pathway, GDF3 plays a critical role in enhancing phagocytosis and bactericidal function in macrophages. Pre- and post-administration of rGDF3 could attenuate polymicrobial sepsis-induced inflammation, organ damage, and mortality in mice. Therefore, GDF3 may be of great interest as a potential drug target or mediator to improve clinical outcomes for sepsis patients.

\section{DATA AVAILABILITY STATEMENT}

The raw data supporting the conclusions of this article will be made available by the authors, without undue reservation. 


\section{ETHICS STATEMENT}

The animal study was reviewed and approved by University of Cincinnati Animal Care and Use Committee.

\section{AUTHOR CONTRIBUTIONS}

PW designed and performed experiments, analyzed data and wrote the manuscript. XM designed experiments, helped to conduct flow cytometry experiments, and critically reviewed the manuscript. HZ, YL, LW, S-NC, and XW assisted with various experiments and critically reviewed the manuscript. VW and BZ helped to sacrifice LXR $\alpha-\mathrm{KO}$ mice and collect samples. TP and CW helped with experimental design, data analysis, and critically reviewed the manuscript. G-CF analyzed results, reviewed/edited manuscript, provided financial and administrative

\section{REFERENCES}

1. Angus DC, Van der Poll T. Severe sepsis and septic shock. NEngl J Med. (2013) 369:840-51. doi: 10.1056/NEJMra1208623

2. Engel C, Brunkhorst FM, Bone HG, Brunkhorst R, Gerlach $H$, Grond S, et al. Epidemiology of sepsis in Germany: results from a national prospective multicenter study. Intensive Care Med. (2007) 33:606-18. doi: 10.1007/s00134-006-0517-7

3. Cohen J, Vincent JL, Adhikari NK, Machado FR, Angus DC, Calandra T, et al. Sepsis: a roadmap for future research. Lancet Infect Dis. (2015) 15:581614. doi: 10.1016/S1473-3099(15)70112-X

4. Rudd KE, Johnson SC, Agesa KM, Shackelford KA, Tsoi D, Kievlan DR, et al. Global, regional, and national sepsis incidence and mortality, 1990-2017: analysis for the Global Burden of Disease Study. Lancet. (2020) 395:20011. doi: 10.1016/S0140-6736(19)32989-7

5. Torgersen C, Moser P, Luckner G, Mayr V, Jochberger S, Hasibeder WR, et al. Macroscopic postmortem findings in 235 surgical intensive care patients with sepsis. Anesth Analg. (2009) 108:1841-47. doi: 10.1213/ane.0b013e318195e11d

6. Hotchkiss RS, Monneret G, Payen D. Immunosuppression in sepsis: a novel understanding of the disorder and a new therapeutic approach. Lancet Infect Dis. (2013) 13:260-68. doi: 10.1016/S1473-3099(13)70001-X

7. Song Z, Zhang J, Zhang X, Li D, Wang H, Xu X, et al. Interleukin 4 deficiency reverses development of secondary Pseudomonas aeruginosa pneumonia during sepsis-associated immunosuppression. J Infect Dis. (2015) 211:161627. doi: 10.1093/infdis/jiu668

8. Afshar M, Arain E, Ye C, Gilbert E, Xie M, Lee J, et al. Patient outcomes and cost-effectiveness of a sepsis care quality improvement program in a health system. Crit Care Med. (2019) 47:1371-79. doi: 10.1097/CCM.0000000000003919

9. Lee JT, Mikkelsen ME. Risk stratification tools in sepsis: From Acute Physiology and Chronic Health Evaluation to quick sequential organ failure assessment. Crit Care Med. (2019) 47:1159-61. doi: 10.1097/CCM.0000000000003859

10. Csóka B, Németh ZH, Szabó I, Davies DL, Varga ZV, Pálóczi J, et al. Macrophage P2X4 receptors augment bacterial killing and protect against sepsis. JCI Insight. (2018) 3:e99431. doi: 10.1172/jci.insight. 99431

11. Mu X, Wang $\mathrm{P}$, Wang $\mathrm{X}$, Li Y, Zhao H, Li Q, et al. Identification of a novel antisepsis pathway: sectmla enhances macrophage phagocytosis of bacteria through activating GITR. J Immunol. (2020) 205:163343. doi: 10.4049/jimmunol.2000440

12. Rs H, Karl IE. The pathophysiology and treatment of sepsis. $N$ Engl J Med. (2003) 348:138-50. doi: 10.1056/NEJMra021333

13. Martinez FO, Sica A, Mantovani A, Locati M. Macrophage activation and polarization. Front Biosci. (2008) 13:453-61. doi: 10.2741/2692 support, and gave final approval of the manuscript. All authors contributed to the article and approved the submitted version.

\section{FUNDING}

This study was supported by National Institutes of Health (NIH) Grants R01 (GM-126061 and GM-132149 to G-CF), and American Heart Association (AHA) Established Investigator Award (17EIA33400063 to G-CF).

\section{SUPPLEMENTARY MATERIAL}

The Supplementary Material for this article can be found online at: https://www.frontiersin.org/articles/10.3389/fimmu. 2021.647070/full\#supplementary-material
14. Andrews $\mathrm{T}$, Sullivan KE. Infections in patients with inherited defects in phagocytic function. Clin Microbiol Rev. (2003) 16:597-621. doi: 10.1128/CMR.16.4.597-621.2003

15. Anderson P, Souza-Moreira L, Morell M, Caro M, O’Valle F, Gonzalez-Rey E, et al. Adipose-derived mesenchymal stromal cells induce immunomodulatory macrophages which protect from experimental colitis and sepsis. Gut. (2013) 62:1131-41. doi: 10.1136/gutjnl-2012-302152

16. Andersson O, Bertolino P, Ibáñez CF. Distinct and cooperative roles of mammalian Vg1 homologs GDF1 and GDF3 during early embryonic development. Dev Biol. (2007) 311:500-11. doi: 10.1016/j.ydbio.2007.08.060

17. Chen C, Ware SM, Sato A, Houston-Hawkins DE, Habas R, Matzuk MM, et al. The Vg1-related protein Gdf3 acts in a Nodal signaling pathway in the pre-gastrulation mouse embryo. Development. (2006) 133:31929. doi: $10.1242 /$ dev. 02210

18. Levine AJ, Brivanlou AH. GDF3, a BMP inhibitor, regulates cell fate in stem cells and early embryos. Development. (2006) 133:209-16. doi: 10.1242/dev.02192

19. Saitou N, Nei M. The neighbor-joining method: a new method for reconstructing phylogenetic trees. Mol Biol Evol. (1987) 4:406-25. doi: 10.1093/oxfordjournals.molbev.a040454

20. Wu Y, Zuo J, Ji G, Saiyin H, Liu X, Yin F, et al. Proapoptotic function of integrin $\beta 3$ in human hepatocellular carcinoma cells. Clin Cancer Res. (2009) 15:60-9. doi: 10.1158/1078-0432.CCR-08-1028

21. Hexige S, Guo J, Ma L, Sun Y, Liu X, Ma L, et al. Expression pattern of growth/differentiation factor 3 in human and murine cerebral cortex, hippocampus as well as cerebellum. Neurosci Lett. (2005) 389:837. doi: 10.1016/j.neulet.2005.06.071

22. Jörnvall H, Blokzijl A, ten Dijke P, Ibáñez CF. The orphan receptor serine/threonine kinase ALK7 signals arrest of proliferation and morphological differentiation in a neuronal cell line. J Biol Chem. (2001) 276:5140-6. doi: 10.1074/jbc.M005200200

23. Levine AJ, Levine ZJ, Brivanlou AH. GDF3 is a BMP inhibitor that can activate Nodal signaling only at very high doses. Dev Biol. (2009) 325:438. doi: 10.1016/j.ydbio.2008.09.006

24. Varga T, Mounier R, Patsalos A, Gogolák P, Peloquin M, Horvath A, et al. Macrophage PPAR $\gamma$, a lipid activated transcription factor controls the growth factor GDF3 and skeletal muscle regeneration. Immunity. (2016) 45:103851. doi: 10.1016/j.immuni.2016.10.016

25. Patsalos A, Simandi Z, Hays TT, Peloquin M, Hajian M, Restrepo $\mathrm{I}$, et al. In vivo GDF3 administration abrogates aging related muscle regeneration delay following acute sterile injury. Aging Cell. (2018) 17:e12815. doi: 10.1111/acel.12815

26. Wang L, Li Y, Wang X, Wang P, Essandoh K, Cui S, et al. GDF3 protects mice against sepsis-induced cardiac dysfunction and mortality by suppression of macrophage pro-inflammatory phenotype. Cells. (2020) 9:120. doi: $10.3390 /$ cells 9010120 
27. Dejager L, Pinheiro I, Dejonckheere E, Libert C. Cecal ligation and puncture: the gold standard model for polymicrobial sepsis? Trends Microbiol. (2011) 19:198-208. doi: 10.1016/j.tim.2011.01.001

28. Suresh MV, Dolgachev VA, Zhang B, Balijepalli S, Swamy S, Mooliyil J, et al. TLR3 absence confers increased survival with improved macrophage activity against pneumonia. JCI Insight. (2019) 4:e131195. doi: 10.1172/jci.insight.131195

29. Matute-Bello G, Downey G, Moore BB, Groshong SD, Matthay MA, Slutsky AS, et al. An official American Thoracic Society workshop report: features and measurements of experimental acute lung injury in animals. Am J Respir Cell Mol Biol. (2011) 44:725-38. doi: 10.1165/rcmb.2009-0210ST

30. Wang J, Wu MY, Su H, Lu J, Chen X, Tan J, et al. iNOS interacts with autophagy receptor p62 and is degraded by autophagy in macrophages. Cells. (2019) 8:1255. doi: 10.3390/cells8101255

31. Kaneko M, Emoto Y, Emoto M. A simple, reproducible, inexpensive, yet oldfashioned method for determining phagocytic and bactericidal activities of macrophages. Yonsei Med J. (2016) 57:283-90. doi: 10.3349/ymj.2016.57.2.283

32. Gao X, Yan X, Zhang Q, Yin Y, Cao J. CD5L contributes to the pathogenesis of methicillin-resistant Staphylococcus aureus-induced pneumonia. Int Immunopharmacol. (2019) 72:40-7. doi: 10.1016/j.intimp.2019.03.057

33. Joseph SB, Bradley MN, Castrillo A, Bruhn KW, Mak PA, Pei L, et al. LXR-dependent gene expression is important for macrophage survival and the innate immune response. Cell. (2004) 119:299-309. doi: 10.1016/j.cell.2004.09.032

34. Crisafulli C, Mazzon E, Paterniti I, Galuppo M, Bramanti P, Cuzzocrea S. Effects of Liver $\mathrm{x}$ receptor agonist treatment on signal transduction pathways in acute lung inflammation. Respir Res. (2010) 11:19. doi: 10.1186/1465-9921-11-19

35. Prüfer K, Boudreaux J. Nuclear localization of liver $\mathrm{X}$ receptor $\alpha$ and $\beta$ is differentially regulated. J Cell Biochem. (2007) 100:69-85. doi: 10.1002/jcb.21006

36. Hu W, Zhang W, Chen Y, Rana U, Teng RJ, Duan Y, et al. Nogo-B receptor deficiency increases liver $\mathrm{X}$ receptor alpha nuclear translocation and hepatic lipogenesis through an adenosine monophosphate-activated protein kinase alpha-dependent pathway. Hepatology. (2016) 64:155976. doi: 10.1002/hep. 28747

37. Hotchkiss RS, Moldawer LL, Opal SM, Reinhart K, Turnbull IR, Vincent JL. Sepsis and septic shock. Nat Rev Dis Primers. (2016) 2:1-21. doi: 10.1038/nrdp.2016.45

38. Danikas DD, Karakantza M, Theodorou GL, Sakellaropoulos GC, Gogos CA. Prognostic value of phagocytic activity of neutrophils and monocytes in sepsis. Correlation to CD64 and CD14 antigen expression. Clin Exp Immunol. (2008) 154:87-97. doi: 10.1111/j.1365-2249.2008.03737.x

39. Uderhardt S, Martins AJ, Tsang JS, Lämmermann T, Germain RN. Resident macrophages cloak tissue microlesions to prevent neutrophil-driven inflammatory damage. Cell. (2019) 177:541-55. doi: 10.1016/j.cell.2019.02.028

40. Belikoff BG, Hatfield S, Georgiev P, Ohta A, Lukashev D, Buras JA, et al. A2B adenosine receptor blockade enhances macrophage-mediated bacterial phagocytosis and improves polymicrobial sepsis survival in mice. J Immunol. (2011) 186:2444-53. doi: 10.4049/jimmunol.1001567

41. Ma H, Kou J, Zhu D, Yan Y, Yu B. Liu-Shen-Wan, a traditional Chinese medicine, improves survival in sepsis induced by cecal ligation and puncture via reducing TNF- $\alpha$ levels, MDA content and enhancing macrophage phagocytosis. Int Immunopharmacol. (2006) 6:1355-62. doi: 10.1016/j.intimp.2006.03.003

42. Gong D, Shi W, Yi SJ, Chen H, Groffen J, Heisterkamp N. TGF $\beta$ signaling plays a critical role in promoting alternative macrophage activation. BMC Immunol. (2012) 13:1-10. doi: 10.1186/1471-2172-13-31
43. Wang B, Tontonoz P. Liver $\mathrm{X}$ receptors in lipid signalling and membrane homeostasis. Nat Rev Endocrinol. (2018) 14:45263. doi: 10.1038/s41574-018-0037-x

44. Svensson PA, Hägg DA, Jernås M, Englund MC, Hulten LM, Ohlsson BG, et al. Identification of genes predominantly expressed in human macrophages. Atherosclerosis. (2004) 177:287-90. doi: 10.1016/j.atherosclerosis. 2004.07.031

45. Bookout AL, Jeong Y, Downes M, Ruth TY, Evans RM, Mangelsdorf DJ. Anatomical profiling of nuclear receptor expression reveals a hierarchical transcriptional network. Cell. (2006) 126:78999. doi: 10.1016/j.cell.2006.06.049

46. Matalonga J, Glaria E, Bresque M, Escande C, Carbó JM, Kiefer K, et al. The nuclear receptor LXR limits bacterial infection of host macrophages through a mechanism that impacts cellular NAD metabolism. Cell Rep. (2017) 18:1241-55. doi: 10.1016/j.celrep.2017.01.007

47. Miyazaki T, Hirokami Y, Matsuhashi N, Takatsuka H, Naito M. Increased susceptibility of thymocytes to apoptosis in mice lacking AIM, a novel murine macrophage-derived soluble factor belonging to the scavenger receptor cysteine-rich domain superfamily. J Exp Med. (1999) 189:41322. doi: 10.1084/jem.189.2.413

48. Martinez VG, Escoda-Ferran C, Tadeu Simões I, Arai S, Orta Mascaró $\mathrm{M}$, Carreras E, et al. The macrophage soluble receptor AIM/Api6/CD5L displays a broad pathogen recognition spectrum and is involved in early response to microbial aggression. Cell Mol Immunol. (2014) 11:34354. doi: $10.1038 / \mathrm{cmi} .2014 .12$

49. Sanjurjo L, Amézaga N, Aran G, Naranjo-Gómez M, Arias L, Armengol C, et al. The human CD5L/AIM-CD36 axis: a novel autophagy inducer in macrophages that modulates inflammatory responses. Autophagy. (2015) 11:487-502. doi: 10.1080/15548627.2015. 1017183

50. Sanjurjo L, Amézaga N, Vilaplana C, Cáceres N, Marzo E, Valeri M, et al. The scavenger protein apoptosis inhibitor of macrophages (AIM) potentiates the antimicrobial response against Mycobacterium tuberculosis by enhancing autophagy. PLoS ONE. (2013) 8:e79670. doi: 10.1371/journal.pone.0079670

51. Arai S, Miyazaki T. A scavenging system against internal pathogens promoted by the circulating protein apoptosis inhibitor of macrophage (AIM). Semin Immunopathol. (2018) 40:567-75. doi: 10.1007/s00281-018-0717-6

52. Sanjurjo L, Aran G, Roher N, Valledor AF, Sarrias MR. AIM/CD5L: a key protein in the control of immune homeostasis and inflammatory disease. $J$ Leukoc Biol. (2015) 98:173-84. doi: 10.1189/jlb.3RU0215-074R

53. Allen LA, Aderem A. Mechanisms of phagocytosis. Curr Opin Immunol. (1996) 8:36-40. doi: 10.1016/S0952-7915(96)80102-6

54. Niedergang F, Chavrier P. Regulation of phagocytosis by Rho GTPases. Curr Top Microbiol Immunol. (2005) 291:43-60. doi: 10.1007/3-540-27511-8_4

55. Mao Y, Finnemann SC. Regulation of phagocytosis by Rho GTPases. Small GTPases. (2015) 6:89-99. doi: 10.4161/21541248.2014.989785

Conflict of Interest: The authors declare that the research was conducted in the absence of any commercial or financial relationships that could be construed as a potential conflict of interest.

Copyright (c) 2021 Wang, Mu, Zhao, Li, Wang, Wolfe, Cui, Wang, Peng, Zingarelli, Wang and Fan. This is an open-access article distributed under the terms of the Creative Commons Attribution License (CC BY). The use, distribution or reproduction in other forums is permitted, provided the original author $(s)$ and the copyright owner(s) are credited and that the original publication in this journal is cited, in accordance with accepted academic practice. No use, distribution or reproduction is permitted which does not comply with these terms. 